\title{
New Active Pharmaceutical Ingredient-Ionic Liquids (API-ILs) Derived from Indomethacin and Mebendazole ${ }^{\dagger}$
}

\author{
Verónica Fernandez-Stefanuto and Emilia Tojo * \\ Faculty of Chemistry, University of Vigo, Marcosende, As Lagoas, 36210 Vigo, Spain; vefernandez@uvigo.es \\ * Correspondence: etojo@uvigo.es; Tel.: +34-986-81-2290 \\ + Presented at the 22nd International Electronic Conference on Synthetic Organic Chemistry, \\ 15 November-15 December 2018; Available Online: https://sciforum.net/conference/ecsoc-22.
}

Published: 14 November 2018

\begin{abstract}
The transformation of two solid Active Pharmaceutical Ingredients (APIs) into new ionic liquids (IL)s that incorporate APIs (API-ILs) is reported. The structures of the APIs (indomethacin and mebendazole) were selected by their susceptibility to being transformed into API-ILs (either to form the cation or the anion) and their limited bioavailability due to their low solubility in water. The counterions, such as those derived from 2-dimethylaminoethanol (DMEA), tetramethylguanidine (TMG), 1,8-diazabicyclo[5.4.0]undec-7-ene (DBU), 1,4-diazabicyclo[2.2.2] (TED), $p$-toluensulfonic acid, glycolic acid, methanesulfonic acid, and saccharin, were carefully chosen, aiming for high biocompatibility, low toxicity, and high water solubility. The synthesis was carried out by direct treatment of the API with the corresponding selected acid or base. Finally, the solubility in water of all the synthesized salts was determined.
\end{abstract}

Keywords: ionic liquid; active pharmaceutical ingredients; water solubility

\section{Introduction}

The efficiency of a drug or Active Pharmaceutical Ingredient (API) largely depends on its bioavailability [1]. This property is directly related to the permeability of the API and its solubility. Because the accessibility of a drug to its pharmacological target in the body involves its solution in body fluids and the passage through membranes (absorption and distribution), a low solubility leads to a low dissolution rate and absorption, and, consequently, a higher dose to achieve the therapeutic effect [1]. A low solubility in water is one of the main challenges to deal with during the development of active principles for oral administration, one of the most common routes of drugs administration. The API used in the formulations of medicines are commonly found in their crystalline form to maximize their purity, thermal stability, and bioavailability. However, these solid forms have a number of limitations, such as low solubility in water, polymorphism, and difficulty to cross the lipid bilayers due to their insufficient lipophilicity [2].

Considering the unique properties of ionic liquids (ILs), it is not surprising that in recent years they have aroused great interest in biomedical research, not only as a catalytic means for drug synthesis, but also as potential components for the formulations of drugs. In order to solve the disadvantages that drugs have in solid state, new ILs incorporate pharmacological active ingredients into their structures, forming what is known as API-ILs (Active Pharmaceutical Ingredients-ILs), an alternative to common crystalline salts [3].

In this work, two APIs, which are susceptible of being transform into ILs, were selected to improve their solubility in water. The different counterions to form the new API-ILs were chosen based on high biocompatibility, low toxicity, and high water solubility. 


\section{Materials and Methods}

Chemical reactants and solvents were purchased from Sigma Aldrich and Acros-organics. All solvents were distilled prior to use. The glass material employed in the synthetic reactions was dried in an oven at $60^{\circ} \mathrm{C}$ for $24 \mathrm{~h}$ before its use. The evolution of the reactions was monitored by thin layer chromatography (t.l.c.) employing silica-gel sheets (Merck, TLC Silica gel 60 F254). A solution of Hex/AcOEt (2:1) was employed as an eluent.

Spectroscopic data were provided by the Center of Scientific-Technological Support to Research (CACTI) of the University of Vigo. ${ }^{1} \mathrm{H}$ and ${ }^{13} \mathrm{C}$ NMR spectra were recorded on a BRUKER ARX 4CO spectrometer at $400.1621\left({ }^{1} \mathrm{H}\right)$ and $100.6314\left({ }^{13} \mathrm{C}\right) \mathrm{MHz}$, respectively. $\mathrm{CDCl}_{3}$ (ACROS Organics, 99.6+ atom $\% \mathrm{D}$ ) and DMSO (ACROS Organics, $99.5+$ atom $\% \mathrm{D}$ ) were employed as deuterated solvents as received from the supplier.

\section{Results and Discussion}

\subsection{Synthesis}

The synthesis of the eight novel salts was carried out through direct treatment of the API with the corresponding acid or base [4]. Due to their low solubility in water, their pharmacological properties, and their capacity to be transformed into ILs, the selected APIs were indomethacin (water solubility $0.0009 \mathrm{mg} / \mathrm{mL}$, anti-inflammatory) and mebendazole (water solubility $0.09 \mathrm{mg} / \mathrm{mL}$, antihelmintic and antitumor properties). The general synthetic procedures are shown in Figure 1.<smiles>COc1ccc2c(c1)c(CC(=O)O)c(C)n2C(=O)c1ccc(Cl)cc1</smiles>

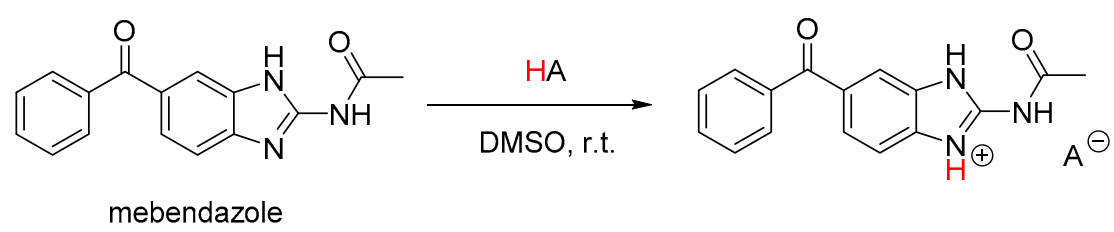

Figure 1. General synthesis of indomethacin and mebendazole based new salts.

The counterions of the ionized APIs were carefully chosen, based on high biocompatibility, low toxicity, and high water solubility. Thus, the bases selected to react with indomethacin, were tetramethylguanidine (TMG), 2-dimethylaminoethanol (DMEA), 1,8-diazabicyclo[5.4.0]undec-7-ene (DBU), and 1,4-diazabicyclo[2.2.2] octane (TED); the acids selected to react with mebendazole were $p$ toluensulfonic acid, glycolic acid, methanesulfonic acid, and saccharin (Figures 2 and 3).

Indomethacin based API-ILs were found to be liquids at room temperature, while those derived from mebendazole were all solid salts.

The structures of all the new synthesized salts were confirmed by ${ }^{1} \mathrm{H}$ and ${ }^{13} \mathrm{C}$ NMR spectroscopy, as well as low and/or high MS spectrometry. 
Anion:<smiles>COc1ccc2c(c1)c(CC(=O)O)c(C)n2C(=O)c1ccc(Cl)cc1</smiles>

Indomethacinate [IND]

\section{Cations:}<smiles></smiles>

[TMG]<smiles>C1CCN2CCCNC2C1</smiles>

[DBU]<smiles>C[NH2+]CCO</smiles>

[DMEA]

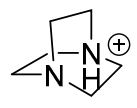

[TED]

Figure 2. Structures of the synthesized indomethacin based active pharmaceutical ingredient-ionic liquids (API-ILs); tetramethylguanidine (TMG); 2-dimethylaminoethanol (DMEA); 1,8diazabicyclo[5.4.0]undec-7-ene (DBU); 1,4-diazabicyclo[2.2.2]octane (TED).

Cation:<smiles></smiles>

Mebendazolium [MEB]

\section{Anions:}<smiles>Cc1ccc(S(=O)(=O)[O-])cc1</smiles><smiles>O=C([O-])CO</smiles>

Glycolate [Gly]<smiles>CS(=O)(=O)[O-]</smiles>

Mesylate [Mes]<smiles>O=C1N[13CH]([O-])S(=O)(=O)c2ccccc21</smiles>

Sacharinate [Sach]

Figure 3. Structures of the synthesized mebendazole based new salts.

\subsection{Solubility Tests}

A solubility test in water was carried out with all the salts synthesized. Water was added drop by drop to a known quantity of each salt ( $50 \mu \mathrm{L}$ each) until completely dissolved. The concentrations $(\mathrm{mg} / \mathrm{mL})$ were then calculated to give the results shown in Tables 1 and 2 . As can be seen, a significant increase in the solubility of the two selected commercial APIs, indomethacin and mebendazole, was obtained.

Table 1. Solubility $(\mathrm{mg} / \mathrm{mL})$ in water of indomethacin based API-ILs.

\begin{tabular}{cccc}
\hline API-IL & State at r.t. & API-IL Solubility & Indomethacin Solubility \\
\hline$[$ TMG][IND] & Liquid & 630 & \\
{$[\mathrm{DMEA}][\mathrm{IND}]$} & Liquid & 620 & 0.0009 \\
{$[\mathrm{DBU}][\mathrm{IND}]$} & Liquid & 500 & \\
{$[\mathrm{TED}][\mathrm{IND}]$} & Liquid & 710 & \\
\hline
\end{tabular}


Table 2. Solubility $(\mathrm{mg} / \mathrm{mL})$ in water of mebendazole based new salts.

\begin{tabular}{cccc}
\hline API-IL & $\begin{array}{c}\text { State at r.t. } \\
\left(\mathbf{m} . \mathbf{p} .{ }^{\circ} \mathbf{C}\right)\end{array}$ & $\begin{array}{c}\text { API-IL } \\
\text { Solubility }\end{array}$ & $\begin{array}{c}\text { Mebendazole } \\
\text { Solubility }\end{array}$ \\
\hline$[\mathrm{MEB}][\mathrm{TsO}]$ & Solid (180) & 4 & \\
{$[\mathrm{MEB}][\mathrm{Gly}]$} & Solid (175) & 25 & 0.09 \\
{$[\mathrm{MEB}][\mathrm{Mes}]$} & Solid (165) & 36 & \\
{$[\mathrm{MEB}][\mathrm{Sac}]$} & Solid (193) & 13 & \\
\hline
\end{tabular}

\section{Conclusions}

With the aim of improving their solubility in water, two solid APIs (indomethacin and mebendazole) were selected to be transformed into new API-ILs. The counterions, such as those derived from DMEA, TMG, DBU, TED, $p$-toluensulfonic acid, glycolic acid, methanesulfonic acid and saccharin, were carefully chosen based on high biocompatibility, low toxicity, and high water solubility. Indomethacin based API-ILs were found to be liquids at room temperature while the new salts derived from mebendazole were all solids, with melting points higher than $100{ }^{\circ} \mathrm{C}$.

The structures of all eight new synthesized salts were confirmed by ${ }^{1} \mathrm{H}$ and ${ }^{13} \mathrm{C} N M R$ spectroscopy as well as low and/or high MS spectrometry.

The solubility tests showed a significant increase of the solubility in water for all the synthesized salts, especially for the API-ILs derived from indomethacin.

Author Contributions: E.T. conceived and designed the experiments; V.F.-S. performed the experiments and analyzed the data; the two authors contributed to writing the proceeding.

Funding: This research received no external funding.

Acknowledgments: We acknowledge the Xunta de Galicia (ED431D 2017/06) for financial support.

Conflicts of Interest: The authors declare no conflict of interest.

\section{References}

1. Jain, S.; Patel, N.; Lin, S. Solubility and dissolution enhacement strategies: current understanding and recent trends. Drug Dev. Ind. Pharm. 2015, 41, 875-887, doi:10.3109/03639045.2014.971027.

2. Hauss, D.J. Oral lipid-based formulations. Adv. Drug Deliv. Rev. 2007, 59, 667-676, doi:10.1016/j.addr.2007.05.006.

3. Shamshina, J.L.; Berton, P.; Wan, H.; Zhou, X.; Gurau, G.; Rogers, R.D. Green Techniques for Organic Synthesis and Medicinal Chemistry, 2nd ed.; Zhang, W., Berkeley W.C., Eds.; John Wiley \& Sons: Hoboken, NJ, USA, 2018, doi:10.1002/9781119288152.

4. Park, H.J.; Prausnitz, M.R. Lidocaine-ibuprofen ionic liquid for dermal anesthesia. AIChE J. 2015, 61, $2732-$ 2738, doi:10.1002/aic.14941

() 2019 by the authors. Licensee MDPI, Basel, Switzerland. This article is an open access article distributed under the terms and conditions of the Creative Commons Attribution (CC BY) license (http://creativecommons.org/licenses/by/4.0/). 